\title{
Physicochemical Characterization and In Vitro Evaluation of the Sun Protection Factor of Cosmetic Products Made from Natural Clay Material
}

\author{
Lawrence M. Madikizela ${ }^{a, \star}$, Ntombentsha Nkwentsha ${ }^{b}$, Nomchenge Y. Mlunguza ${ }^{a}$ and \\ Phumlane S. Mdlulia \\ ${ }^{a}$ Department of Chemistry, Durban University of Technology, P.O. Box 1334, Durban, 4000, South Africa. \\ ${ }^{b}$ Khuselindalo Environmental Development, P.O. Box 804, Port Edward, 4295, South Africa.
}

Received 14 December 2016, revised 4 August 2017, accepted 8 August 2017.

\begin{abstract}
Clay has been widely used as photo protectants in rural places of South Africa. Recently, there are wide range of products which are marketed in South Africa as clay cosmetics which are used for photo protection. In this work, in vitro determination of the sun protection factor (SPF) of newly formulated cosmetics produced from natural clay material from the Bizana region in the Eastern Cape Province of South Africa was performed by spectrophotometric means. The SPF values found for clay material, face cream, foundation, face mask and scrub were 1.18, 18.33, 13.71, 6.74 and 9.53, respectively. The same materials were characterized using thermogravimetric analysis (TGA), Fourier-transform infrared spectroscopy (FTIR), X-ray diffraction (XRD), X-ray fluorescence (XRF), scanning electron microscope (SEM) equipped with energy dispersive spectrometry (EDS) and inductively coupled plasma (ICP). Based on FTIR, XRD, XRF and SEM-EDS results, kaolinite, goethite and quartz were the major minerals found in the clay. Toxic elements such as mercury and cadmium were not detected during ICP analysis; however, traces of lead $\left(0.72-2.14 \mathrm{mg} \mathrm{kg}^{-1}\right)$ and arsenic $\left(0.49-0.69 \mathrm{mg} \mathrm{kg}^{-1}\right)$ were found in cosmetic products. The results obtained in this study indicate that the cosmetic products manufactured from clay have sun protection ability.
\end{abstract}

KEYWORDS

Sun protection factor, cosmetic products, natural clay material.

\section{Introduction}

A large number of South African citizens from the rural areas use raw clay for sun protection. During this practice, the clay material is mixed with water and directly applied onto the skin. In the Eastern Cape Province of South Africa, clay soil is traditionally used for cosmetic applications, especially for cleansing, sunscreen and body beautification. ${ }^{1}$ Globally, sunscreens are manufactured daily as they are able to provide protection against ultraviolet (UV) radiation. Ultraviolet radiation is a type of electromagnetic radiation with wavelengths ranging from 100 to $400 \mathrm{~nm}$. Typically, UV radiation is divided into three types, namely; UV-A (320-400 nm), UV-B (290-320 nm) and UV-C $(100-280 \mathrm{~nm})^{2}{ }^{2}$ Some implications of UV-A radiation on the human skin includes ageing and erythema or sunburn, UV-B may cause DNA damage and skin cancer, whereas UV-C is known to be the highest energy and most dangerous type of UV radiation, but it is generally absorbed by the ozone layer in the atmosphere. ${ }^{3}$ Direct exposure to UV-C radiation for a long period of time is likely to destroy the skin. ${ }^{2}$ While on a positive note, exposure to UV radiation can also result in the synthesis of vitamin D which is essential in the human skin. ${ }^{4}$

In the context of the scope presented above, sunscreen products are formulated with organic and inorganic compounds for UV protection. Titanium dioxide $\left(\mathrm{TiO}_{2}\right)$ and zinc oxide $(\mathrm{ZnO})$ are inorganic compounds that are widely used as physical UV filters. These two inorganic oxides have the ability to reflect UV light and block out sunlight. ${ }^{5}$ Organic UV filters are classified as

* To whom correspondence should be addressed. E-mail: lawrencem2@ dut.ac.za chemical filters that can absorb UV light and thus increasing UV protection. They are usually aromatic compounds that contain a carbonyl group such as cinnamates, benzophenones, etc. ${ }^{4,5}$ Organic filters are used less often, since they can be absorbed into the skin and lead to unwanted reactions.

Cosmetic products are produced with high sun protection factors (SPF) for the purpose of UV protection. SPF is the number that describes the efficiency of the sunscreen product for UV protection. The SPF number can be further explained as the ratio of the least amount of ultraviolet energy required to produce a minimal erythema on sunscreen protected skin, to the amount of energy required to produce the same erythema on unprotected skin. ${ }^{6}$ Analytical methods that have been previously reported for the in vitro determination of SPF include the use of UV spectrophotomer, ${ }^{2}$ mass spectrometry, ${ }^{7}$ and ultraviolet transmittance analyzer. ${ }^{8}$ Based on ease of operation, affordability, availability and small sample size required, UV spectrophotometer was selected as a technique of choice in the current study for the rapid determination of SPF in natural clay material and clay-based formulated cosmetic products.

Therefore, the objective of this work was to determine the SPF of newly formulated cosmetic products made from natural clay material. The study also focused on the characterization of natural clay material collected from the Bizana region of the Eastern Cape Province in South Africa. This natural resource from Bizana is of importance as it is widely used by people in the Eastern Cape Province for various traditional activities that include Xhosa weddings and initiation ceremonies. ${ }^{9}$ Regardless 
of the high importance and usage of this natural resource, there is currently no available data on its characterization and sun protection ability. Furthermore, there are currently no toxicological data for the determination of the risks/health effects associated with the usage of clay material for traditional activities or cosmetic applications. Moreover, most people in rural areas in the Eastern Cape Province cannot afford the expensive cosmetic products that are currently marketed in South Africa, therefore, they tend to use this natural resource for sun protection and beautification.

\section{Experimental}

2.1. Cosmetic Products, Clay Samples and Sampling Location Natural clay sample which was used in the manufacture of cosmetic products was collected from rural location in Bizana which is a small town located in the Eastern Cape Province of South Africa. The rural location is situated approximately $55 \mathrm{~km}$ from Bizana town. The town itself is located at a distance of about $250 \mathrm{~km}$ south of Durban Metropolitan City. The samples were dug out using a spade and collected in a plastic container, thereafter they were transported into the laboratory. On arrival in the laboratory, mortar and pestle were used to grind the samples prior to analysis. Cosmetic products manufactured from natural clay and marketed as face cream, foundation, face mask and scrub were analyzed in this study. Such products were kindly donated by a local cosmetic manufacturing company. Commercially available cosmetic products purchased from local supermarkets in Durban, South Africa were used as control samples.

\subsection{In Vitro Evaluation of the Sun Protection Factor}

A sample of $1 \mathrm{~g}$ was transferred to a $100 \mathrm{~cm}^{3}$ volumetric flask followed by the addition of high performance liquid chromatography grade ethanol ( $\geq 99.8 \%$ ) from Sigma-Aldrich (Steinheim, Germany) to the calibration mark. The resulting solution was filtered through a Whatman number one filter paper from Whatman International Ltd (Maidstone, England). $10 \mathrm{~cm}^{3}$ of the sample was withdrawn from the initial solution and diluted to $200 \mathrm{~cm}^{3}$. Thereafter, the absorbance of $10 \mathrm{~cm}^{3}$ of the diluted solution was recorded in the wavelength range of 290-320 nm using a Varian Cary 50 ultraviolet/visible (UV/Vis) spectrophotometer from Agilent Technologies Co Ltd (California, United States). The SPF of natural clay material and cosmetic products was calculated using Equation (1): $:$,10

$$
\mathrm{SPF}=\mathrm{CF} \times \Sigma_{290}^{320} \mathrm{EE}(\lambda) \times \mathrm{I}(\lambda) \times \operatorname{Abs}(\lambda)
$$

where, $\mathrm{CF}$ is the correction factor, $\lambda$ is the wavelength, $\mathrm{EE}$ is the erythemal effect, $\mathrm{I}$ is the solar intensity spectrum and Abs is the absorbance of the diluted sample. Each analysis was performed in triplicate.

\subsection{Physicochemical Characterization}

Natural clay samples were crushed into fine powder and dried for $2 \mathrm{~h}$ in an oven set at $100{ }^{\circ} \mathrm{C}$ from Scientific Engineering (Pty) Ltd (Industria, South Africa). Elemental analysis was performed using a CHNS/O analyzer obtained from Perkin Elmer (Massachusetts, United States). X-ray diffraction (XRD) equipped with XRD commander for data collection and Eva software for processing was obtained from Bruker AXSD8 diffractometer (Karlsruhe, Germany). The diffractometer was coupled with $\mathrm{CuK} \alpha$ radiation $(\lambda=1.5406 \AA)$ at $40 \mathrm{kV}, 40 \mathrm{~mA}$ in a $2 \theta$ range of $10^{\circ}$ to $70^{\circ}$. Thermogravimetric analysis (TGA) equipment was sourced from Mettler (Greifensee, Switzerland).
Fourier-transform infrared spectroscopy (FTIR) equipped with attenuated total reflection from Perkin Elmer (Llantrisant, United Kingdom) was used. Natural clay and clay-based cosmetic formulations were analyzed without any sample pre-treatment.

Scanning electron microscope (SEM) equipped with energy dispersive spectrometry (EDS) from Oxford Instruments (Abingdon, Oxfordshire) was used to study the elemental composition in a clay sample that was coated with gold for high resolution. Samples were further evaluated by independent external laboratories where elemental contents and oxides present in cosmetic products and clay material were determined. Elements were quantified with inductively coupled plasma (ICP) equipped with mass spectrometry detection after the drying and microwave digestion of the samples. Oxide analysis and loss of ignition were performed with $\mathrm{x}$-ray fluorescence (XRF) equipment.

Physicochemical properties such as $\mathrm{pH}$, electrical conductivity (EC), dissolved oxygen (DO), salinity, and total dissolved solids (TDS) were measured using a Bante900P multi-parameter meter from Bante instruments (Shanghai, China). Prior to the use, the equipment was calibrated for $\mathrm{pH}$ and conductivity in our laboratory using the calibration buffers of $\mathrm{pH} 4,7$ and 10 , and also the conductivity solutions of $12.88,84.0$ and $1413 \mu \mathrm{S} \mathrm{cm}^{-1}$ that were provided by the supplier. Prior to analysis, samples were treated using the optimized procedures reported in literature. ${ }^{1,11}$ This was done by preparing slurry solutions of 1:5 sample to deionized water ratio (by mass), followed by stirring the slurry at constant speed for $3 \mathrm{~h}$.

\section{Results and Discussion}

\subsection{In Vitro Determination of the Sun Protection Factor}

Commercial cosmetic products with SPF of 15 and $50+$ as indicated by respective manufacturers were used in order to determine the accuracy and precision of the proposed SPF method. Average SPF of 17.70 and 50.76 were obtained for such commercial products which indicated that the method used in this study is accurate. Whereas, the \% RSD values of 3.40 and 3.01 are an indication of the good precision. Therefore, the current SPF method was applied in the analysis of newly formulated cosmetic products and natural clay material.

The results in Table 1 show the treatment of data in order to determine the SPF of the samples. Table 1 shows the data that was obtained during the determination of the SPF of a commercial available product. In each case, the absorbance values recorded at various wavelengths are given. The normalized product functions $(\mathrm{EE} \times \mathrm{I})$ used are those available in literature. $^{12,13}$

Table 1 SPF calculated for a commercial cream with an SPF of 15.

\begin{tabular}{clll}
\hline $\begin{array}{c}\text { Wavelength } \\
(\mathrm{nm})\end{array}$ & EE $\times$ I & ABS & SPF \\
\hline 290 & 0.0150 & 0.091 & 0.01365 \\
295 & 0.0817 & 0.090 & 0.07353 \\
300 & 0.2874 & 0.088 & 0.2529 \\
305 & 0.3278 & 0.088 & 0.2885 \\
310 & 0.1864 & 0.090 & 0.1678 \\
315 & 0.0839 & 0.088 & 0.07383 \\
320 & 0.0180 & 0.082 & 0.01476 \\
SPF (diluted sample) & & & 0.8849 \\
SPF & & & 17.70 \\
\hline
\end{tabular}

$\mathrm{CF}=10$ 
Table 2 SPF and \% RSD $(n=3)$ values of commercially available cosmetic creams, natural clay and cosmetic products formulated from natural clay material.

\begin{tabular}{lr}
\hline Sample & \multicolumn{1}{c}{ SPF } \\
\hline SPF 50+ & $50.76 \pm 3.40$ \\
SPF 15 & $17.70 \pm 3.01$ \\
Face cream & $18.33 \pm 0.45$ \\
Foundation & $13.71 \pm 1.00$ \\
Face mask & $6.74 \pm 6.52$ \\
Scrub & $9.53 \pm 3.17$ \\
Clay soil & $1.18 \pm 6.50$ \\
\hline
\end{tabular}

$\%$ RSD are given as \pm values

Table 2 shows the SPF values determined for each formulated products including the control samples (SPF 15 and 50+). It was observed that the natural clay material from Eastern Cape which was used in the formulation of the cosmetic products has low SPF value of 1.18. Although the SPF for this material is low, it is widely used as it is known to have the ability to cleanse the skin and to absorb the oils from the skin. These results are in close agreement with the data in literature, for instance, the SPF of natural clay materials used for cosmetic purposes in Kenya is in the range of 1.46 to $5.59 .{ }^{14} \mathrm{SPF}$ was improved to between 9.53 and 18.33 in newly formulated clay-based cosmetic products due to the introduction of inorganic compounds such as $\mathrm{TiO}_{2}$ during their manufacturing process as shown in Table 2.

\subsection{Characterization of Clay Material and Cosmetic Products}

\subsubsection{Thermal Analysis}

The TGA data for natural clay material given in Fig. 1, shows the weight loss of the material as a function of temperature. The weight loss that occurred at around $100{ }^{\circ} \mathrm{C}$ was attributed to the loss of water molecules adsorbed at the surface of the natural clay material. Further weight loss was observed between 250 and $300{ }^{\circ} \mathrm{C}$ which was due to the conversion of goethite into hematite. As documented in literature, ${ }^{15}$ the weight loss above $450{ }^{\circ} \mathrm{C}$ corresponds to the dehydration of inorganic matter such as kaolinite, illite and chlorite. The obtained results from TGA curve were in agreement with the one published for clay that was sampled in Brazil. ${ }^{16}$

\subsubsection{Physicochemical Parameters}

Natural clay material was examined using $\mathrm{CHN}$ analyzer in order to confirm the presence of organic materials. The results obtained from elemental analysis showed that the clay material contained $0.69,1.58$ and $0.04 \%$ of carbon, hydrogen and nitrogen, respectively. Carbon and hydrogen contents are very low and are coherent with very low content of organic matter. This small amount of the organic matter correlate well with the decomposition between 250 and $300^{\circ} \mathrm{C}$ in the TGA data (Fig. 1).

The studied physicochemical properties are presented in Table 3. A commercial cosmetic cream with SPF 15 was used as a reference and identified as the control sample. The $\mathrm{pH}$ obtained for natural clay material was 4.9 which is in agreement with the results obtained previously in another South African study, where the $\mathrm{pH}$ of soil samples from Eastern Cape Province ranged from 4.53 to $9.57 .{ }^{1}$ The reported $\mathrm{pH}$ range for clay samples collected in southern Africa was 2-9. ${ }^{17}$ The $\mathrm{pH}$ for newly formulated cosmetic products from natural clay material ranged from 4.94 for scrub to 6.97 for face mask, whereas in a published work, the $\mathrm{pH}$ of about 6.6 was reported for anti-ageing cosmetic emulsions containing vitamin E acetate as active ingredient. ${ }^{18}$ Furthermore, these results agreed well with the $\mathrm{pH}$ of 6.6 obtained for emulsion cream that was formulated with natural plant extract. ${ }^{19}$ The electrical conductivity of natural clay material was $315 \mu \mathrm{S} \mathrm{cm}^{-1}$, this value was unexpectedly low in all cosmetic products including the control sample which indicated that all the samples were non-saline. This was further confirmed in low salinity results of respective samples. Measuring the electrical conductivity in natural clay material and clay-based formulations is very important as this could allow for the estimation of the soluble salt concentration which in turn is related to the salinity. ${ }^{11}$ TDS values were low when compared to the values reported for soils $\left(246-455 \mathrm{mg} \mathrm{L}^{-1}\right)$ obtained from Libya. ${ }^{11}$ Dissolved oxygen for the new cosmetic products matched well with those of the existing sample used as the control.

\subsubsection{X-ray Diffraction for Natural Clay Material}

Preliminary work on the presence of minerals in the natural clay material was evaluated using XRD. Amongst the other applications of XRD is to study the mineralogical composition of the raw material components. ${ }^{20}$ XRD results presented in Fig. 2 indicated the presence of kaolinite, goethite and quartz as three major minerals in the natural clay material. The peaks were assigned by following the data available in literature for minerals. $^{21-23}$

\subsubsection{Functional Group Analysis of Clay and Cosmetic Products}

The contents of natural clay material were further analyzed using FTIR (Fig. 3). The infrared spectrum for raw natural clay

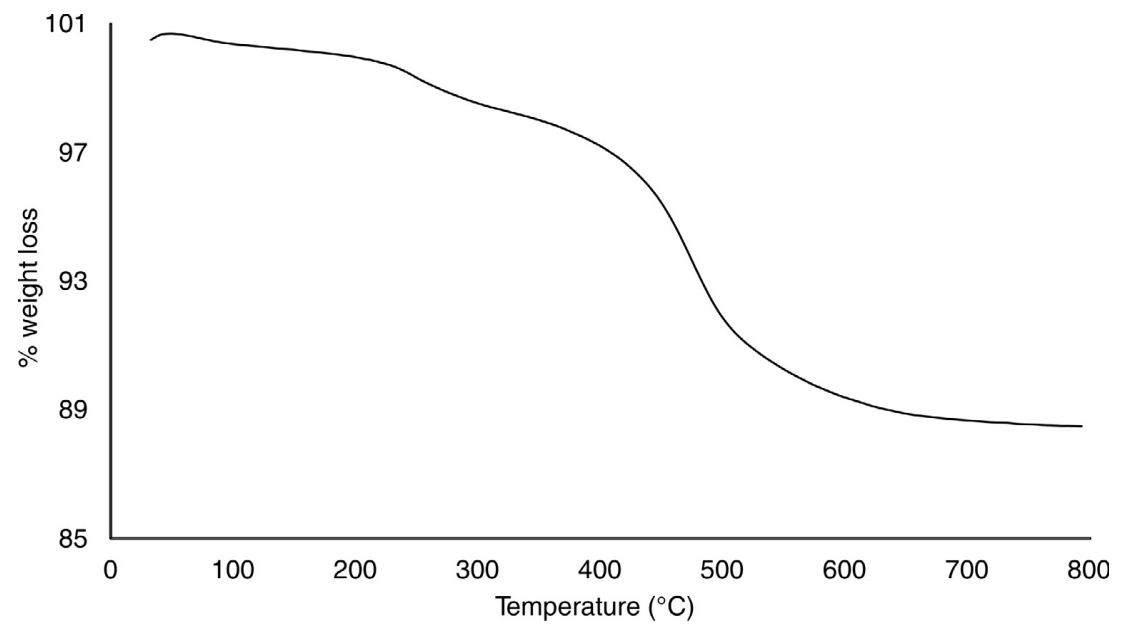

Figure 1 Thermogravimetric analysis of clay material. 
Table 3 Physicochemical properties of clay and cosmetic products.

\begin{tabular}{lcccccc}
\hline \multirow{2}{*}{ Parameter } & \multicolumn{9}{c}{ Sample } \\
\cline { 2 - 7 } & Clay & Face mask & Foundation & Scrub & Face cream & Control \\
\hline pH & 4.929 & 6.974 & 6.851 & 4.942 & 5.043 & 7.03 \\
EC $\left(\mu \mathrm{S} \mathrm{cm}^{-1}\right)$ & 315 & 97.6 & 199.2 & 63.7 & 87.3 & 143.6 \\
Salinity (psu) & 0.17 & 0.05 & 0.10 & 0.04 & 0.05 & 0.07 \\
DO $\left(\mathrm{mg} \mathrm{L}^{-1}\right)$ & 5.63 & 4.39 & 5.82 & 3.83 & 4.23 & 4.72 \\
TDS $\left(\mathrm{mg} \mathrm{L}^{-1}\right)$ & 81.3 & 49.5 & 100.2 & 32.0 & 43.3 & 72.5 \\
\hline
\end{tabular}

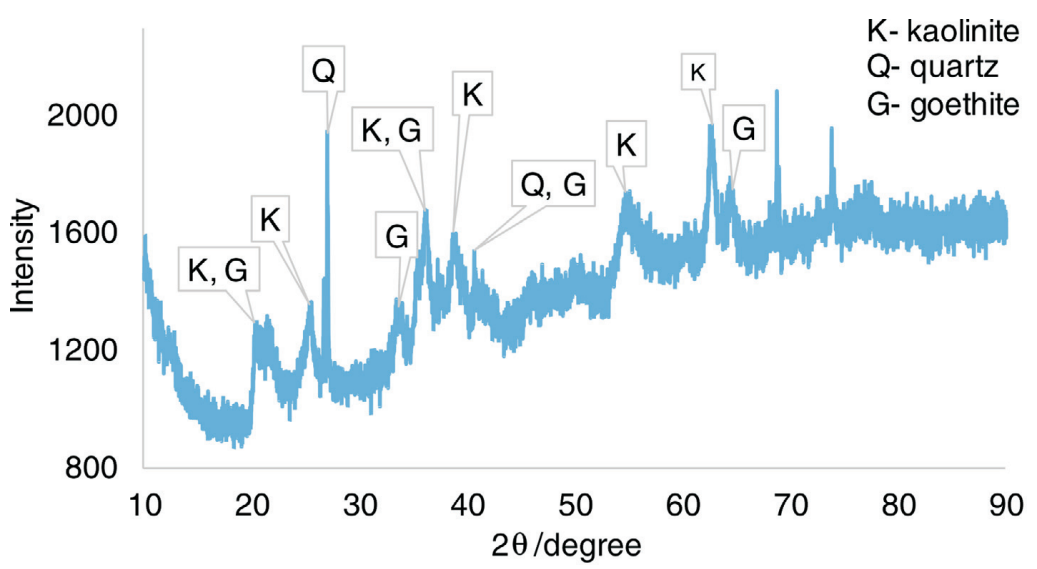

Figure 2 X-ray diffractogram of clay (CuK $\alpha$ radiation $(\lambda=1.5406 \AA)$ at $40 \mathrm{kV}, 40 \mathrm{~mA}$ in a $2 \theta$ range of $10^{\circ}$ to $\left.70^{\circ}\right)$.

was similar to that obtained for the study of clay reported in Nigeria. ${ }^{22}$ The characteristic peaks of kaolinite were observed at $3696,3619,1000$ and $913 \mathrm{~cm}^{-1}$, which are in relation with the data obtained from XRD. The $\mathrm{OH}$ bands were observed at 3696 and $3619 \mathrm{~cm}^{-1}$, whereas there was Al-O bending at $913 \mathrm{~cm}^{-1}$ which could be linked to the presence of aluminosilicate mineral. ${ }^{21}$ It has been reported that pure kaolinite exhibits two peaks at 797 and $750 \mathrm{~cm}^{-1}$ and a well crystallized kaolinite exhibits two sharp peaks at 3690 and $3620 \mathrm{~cm}^{-1}$. ${ }^{22}$ Furthermore, FTIR spectra obtained for cosmetic products (Fig. 4 and Table 4) showed the existence of new peaks at 3287, 2918, 2849 and $1465 \mathrm{~cm}^{-1}$ that were due to the additives used in cosmetic formulations. Examples of such additives are stearic acid and glycerine.

\subsubsection{Scanning Electron Microscopy and Elemental Composition of Raw Clay}

Results for SEM coupled with EDS are presented in Fig. 5. Based on elemental composition, a ratio of 1:1 for silicon/alu- minium composition was observed which could be translated to the presence of kaolinite which correlates with FTIR and XRD data. Kaolinite is an important soil mineral, as it has important uses in pharmaceutical preparations that include being a diluent and binder, emulsifying, thickening and anticaking agent, flavour corrector and carrier-releaser of active principles. ${ }^{25} \mathrm{High}$ amount of oxygen (58.8\%) was observed, as reported for the clay samples that were collected in northern Cameroon. ${ }^{24}$ Other elements found in clay were carbon $(\mathrm{C})$, magnesium $(\mathrm{Mg})$, aluminium (Al), silicon ( $\mathrm{Si}$ ) and iron (Fe). The same elements were found in cosmetic products using ICP analysis, where the concentration $\left(\mathrm{mg} \mathrm{kg}^{-1}\right)$ ranges for magnesium, aluminium, silicon and iron were 176-2660, 10129-69844, 873-1364 and 9838-54529, respectively. These elemental concentrations are comparable with those found in clay soils elsewhere. ${ }^{26}$ For example, the concentration of iron obtained in soil samples from Tanzania ranged from 13567 to $160850 \mu \mathrm{g} \mathrm{g}{ }^{-1} \cdot{ }^{26} \mathrm{~A}$ better distribution map of these elements can be seen in the SEM EDS maps

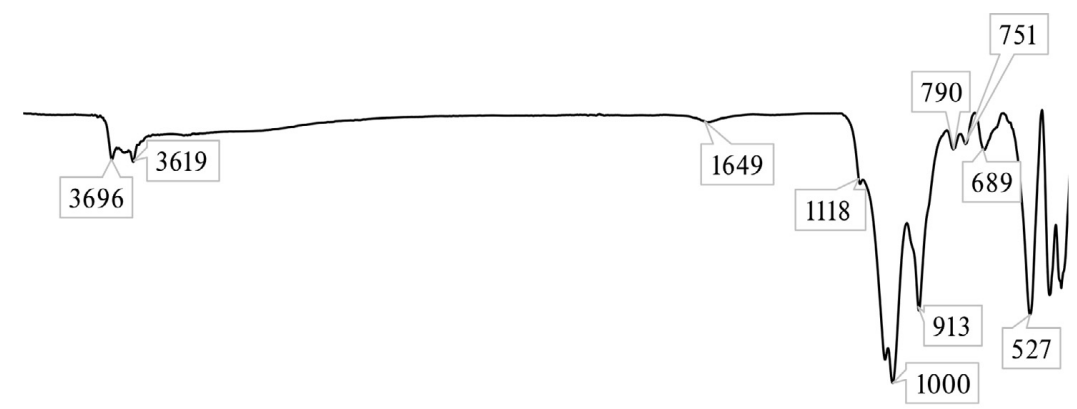

\begin{tabular}{lllccccc}
\hline 3900 & 3400 & 2900 & $\begin{array}{c}2400 \\
\text { Wavenumber } / \mathrm{cm}^{-1}\end{array}$ & 1400 & 900 & 400
\end{tabular}

Figure 3 Fourier transform infrared spectrum of clay. 


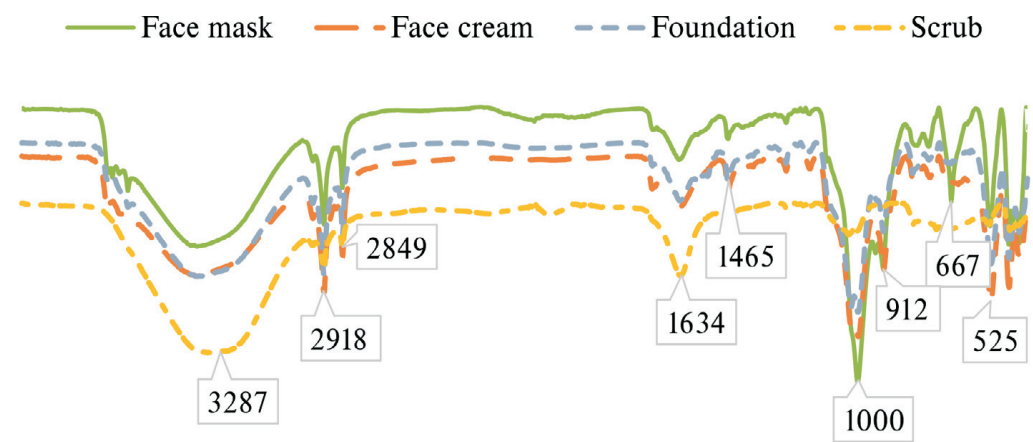

$\begin{array}{lllcccc}3900 & 3400 & 2900 & \begin{array}{c}2400 \\ \text { Wavenumber } / \mathrm{cm}^{-1}\end{array} & 1900 & 1400 & 900\end{array}$

Figure 4 Fourier transform infrared spectrum of cosmetic products manufactured from clay material.

Table 4 Major FTIR bends recorded for natural clay material and cosmetic products sample.

\begin{tabular}{llll}
\hline Wavenumber $\left(\mathrm{cm}^{-1}\right)$ & Sample & Proposed signal & References \\
\hline $3619-3696$ & Clay & O-H stretch usually observed in kaolinite-based clay & 24,15 \\
$3287,2918,2849$, & Cosmetics & Peaks due to additives used in cosmetic formulation & \\
1465 and 525-527 & Clay and all tested cosmetics & O-H bending of water & 24,15 \\
$1634-1649$ & Clay and all tested cosmetics & Si-O-Si vibrations, these may also be due to sulfates and phosphates & 15 \\
$1000-1118$ & Clay and all tested cosmetics & Al-O bend usually observed in aluminosilicate minerals & 24 \\
$912-913$ & All samples & Si-O and Si-O-Fe stretch & 20 \\
$667-689$ & &
\end{tabular}

which were inserted in Fig. 5. These elements are highly important in cosmetic products because of their role on the skin. Such roles include, the use of $\mathrm{Fe}$ as an antiseptic and as cell renewal catalyst, $\mathrm{Si}$ as providing reconstruction of skin tissues, hydration and soothing effect, while $\mathrm{Mg}$ is invigorating. ${ }^{16}$ In addition, ICP results indicated the presence of trace amounts of lead and arsenic in cosmetic products, while mercury and cadmium were not detected (Table 5). Some toxic elements such as mercury and

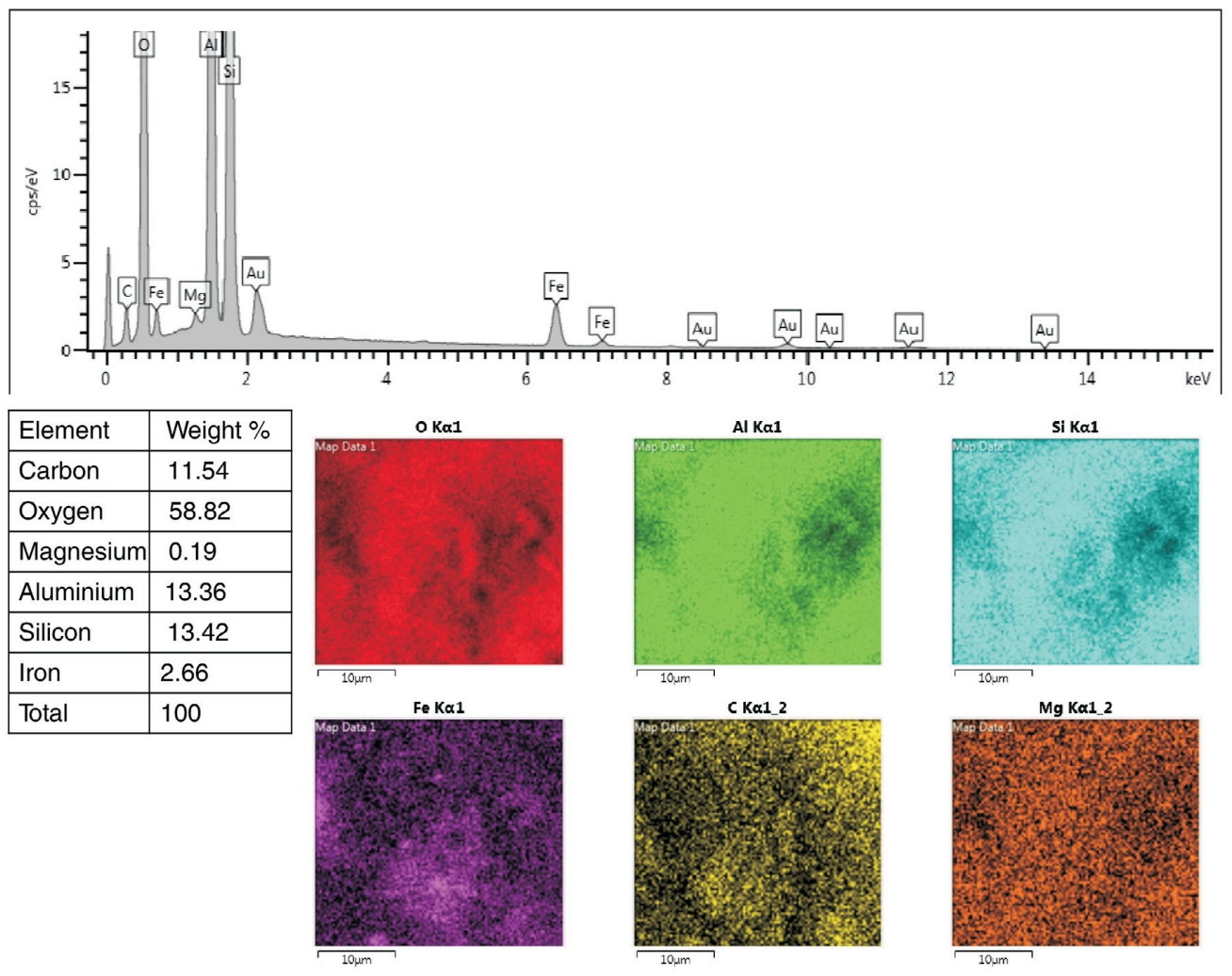

Figure 5 Results for SEM of clay coupled with EDS spectrum. 
Table 5 Element analysis in cosmetic products.

\begin{tabular}{lcccc}
\hline \multirow{2}{*}{ Element } & \multicolumn{4}{c}{ Concentration $\left(\mathrm{mg} \mathrm{kg}^{-1}\right)$} \\
\cline { 2 - 5 } & Face mask & Face cream & Foundation & Scrub \\
\hline Lead & 2.14 & 0.72 & 1.48 & 1.07 \\
Mercury & nd & nd & nd & nd \\
Arsenic & 0.69 & nd & 0.60 & 0.49 \\
Cadmium & nd & nd & nd & nd \\
\hline
\end{tabular}

nd $=$ not detected.

Detection limits: lead and mercury $=0.042 \mathrm{mg} \mathrm{kg}^{-1}$; arsenic and cadmium $=$ $0.083 \mathrm{mg} \mathrm{kg}^{-1}$.

cadmium were not detected in any cosmetic products. Both lead and arsenic have been detected in cosmetic products. Such elements can be allocated in the structure of clay minerals or their accompanying accessory phases, or adsorbed on clay particles. ${ }^{27}$ The presence of carbon in clay could be an indication of organic contamination which correlate with the results obtained with CHN analyzer and TGA.

\subsubsection{Chemical Composition of the Raw Clay}

The main oxides detected in clay using XRF were $\mathrm{Al}_{2} \mathrm{O}_{3}$ $(27.75 \%), \mathrm{SiO}_{2}(37.83 \%)$ and $\mathrm{Fe}_{2} \mathrm{O}_{3}(19.01 \%)$ (Table 6). The iron content is evidence for the presence of iron based minerals such as goethite or hematite and this was confirmed in both TGA and $X R D$. These are the same oxides that were detected in the clay materials from the north of Cameroon. ${ }^{28}$ The presence of $\mathrm{Al}_{2} \mathrm{O}_{3}$, $\mathrm{Fe}_{2} \mathrm{O}_{3}$ and $\mathrm{SiO}_{2}$ confirmed the occurrence of kaolinite, goethite and quartz (indicated in XRD data), respectively. The amount of $\mathrm{TiO}_{2}$ found in the clay was $1.44 \%$, which could play a significant role as a physical UV filter due to its ability for reflection of UV light and blocking out of sunlight. Overall, the oxides detected in this study were also detected in other clay samples originating from other African countries such as Tunisia, Nigeria, Ivory Coast, Guinea and Senegal. ${ }^{29-31}$ In addition, the loss of ignition $(12.55 \%)$ is in agreement with the results reported elsewhere for clay deposits sampled from KwaZulu-Natal and Limpopo provinces of South Africa. ${ }^{32}$ The loss of ignition is attributed to organic matter and the value obtained in this study is coherent with kaolinite rich clay, for which 13-14 \% loss of ignition is known as a mean value. .334 $^{33,3}$

\section{Conclusions}

The calculated SPF values of both commercial products were in close agreement with the labelled SPF values, and were used to validate all SPF calculations which are reported herein. Cosmetic products manufactured from natural clay material have high SPF values, and they can be used for cleansing the skin, emulsification, beautification, adsorption and detoxification. The natural clay itself has been used over the years for traditional purposes in the Eastern Cape Province of South Africa. The natural clay had a low SPF value, thus, this indicated that it can provide very low UV protection. The low UV protection of the raw clay justified the presence of other reagents such as $\mathrm{TiO}_{2}$ to increase the SPF value. The newly formulated products are affordable to the local citizens and made from the natural material that is not hazardous on the human skin. The characterization of natural clay material using XRD, XRF, FTIR and SEM indicated the presence of kaolinite, goethite and quartz as major minerals in the sample. Elements detected in raw clay using EDS were carbon, oxygen, magnesium, aluminium, silicon and iron; which were further confirmed with ICP. Physicochemical characterization results such as $\mathrm{pH}$, conductivity and salinity agreed well with the data in literature.
Table 6 Chemical composition of clay.

\begin{tabular}{lr}
\hline Oxide & Content $\%$ \\
\hline $\mathrm{Al}_{2} \mathrm{O}_{3}$ & 27.75 \\
$\mathrm{CaO}$ & 0.03 \\
$\mathrm{Cr}_{2} \mathrm{O}_{3}$ & 0.01 \\
$\mathrm{Fe}_{2} \mathrm{O}_{3}$ & 19.01 \\
$\mathrm{~K}_{2} \mathrm{O}$ & 0.11 \\
$\mathrm{MgO}$ & 0.18 \\
$\mathrm{MnO}$ & 0.05 \\
$\mathrm{Na}_{2} \mathrm{O}$ & 0.02 \\
$\mathrm{P}_{2} \mathrm{O}_{5}$ & 0.07 \\
$\mathrm{SiO}_{2}$ & 37.83 \\
$\mathrm{TiO}_{2}$ & 1.44 \\
Loss of ignition & 12.55 \\
& \\
Total & 99.05 \\
\hline
\end{tabular}

\section{Acknowledgements}

This work is based on the research supported by National Research Foundation (NRF) of South Africa (Grant Numbers: 93986 and 98279). Special thanks go to Mbali T. Mhlongo (3rd year analytical chemistry student at Durban University of Technology) for her involvement on the determination of SPF. We also thank Phunyezwa V. Nkwentsha and her team for sample collection.

\section{References}

1 D.M.E. Matike, G.I.E. Ekosse and V.M. Ngole, Physico-chemical properties of clayey soil used traditionally for cosmetics in Eastern Cape, South Africa. Int. J. Phys. Sci., 2011, 6, 7557-7566.

2 P.P. Maske, S.G. Lokapure, D. Nimbalkar, S. Malavi and J.I. D'souza, In vitro determination of sun protection factor and chemical stability of Rosa kordesii extract gel. J. Pharm. Res., 2013, 7, 520-524.

3 T. Hoang-Minh, T.L. Le, J. Kasbohm and R. Giere, UV-protection characteristics of some clays. Appl. Clay Sci., 2010, 48, 349-357.

4 I. Dusenkova, I. Kusina, J. Malers and L. Berzina-Cimdina, Application of Latvian Illite clays in cosmetic products with sun protection ability. Proceedings of the 10th International Scientific and Practical Conference, 2015, 1, 28-32.

5 N.A. Elmarzugi, E.I. Keleb, A.T. Mohamed, Y.S. Issa, A.M. Hamza, A.A. Layla, M. Salama and A.M. Bentaleb, The relation between sunscreen and skin pathochanges. Int. J. Pharm. Sci. Invention, 2013, 2, 43-52.

6 S. El-Boury, C. Couteau, L. Boulande, E. Paparis and L.J.M. Coiffard, Effect of the combination of organic and inorganic filters on the Sun Protection Factor (SPF) determined by in vitro method. Int. J. Pharm., 2007, 340, 1-5.

7 D.N. de Oliveira, J. Delafiori, M.S. Ferreira and R.R. Catharino, In vitro evaluation of Sun Protection Factor and stability of commercial sunscreens using mass spectrometry. J. Chromatogr. B, 2015, 988, 13-19.

8 P. Wu, L. Huang, Y. Guo and C. Lin, Effects of the novel poly(methyl methacrylate) (PMMA)-encapsulated organic ultraviolet (UV) filters on the UV absorbance and in vitro sun protection factor (SPF). J. Photochem. Photobiol. B: Biology, 2014, 131, 24-30.

9 M.P. Mpako, E.M. Matike, G.I. Ekosse and V.E. Ngole, Ceremonial usage of clays for body painting according to traditional Xhosa culture. Indilinga: Afr. J. Indig. Know. Sys., 2011, 10, 235-244.

10 V.V. da Silva, C.D. Ropke, R.L. de Almeida, D.V. Miranda, C.Z. Kera, D.P. Rivelli, T.C.H. Sawada and S.B.M. Barros, Chemical stability and SPF determination of Pothomorphe umbellata extract gel and photostability of 4-nerolidylcathecol. Int. J. Pharm., 2005, 303, 125-131.

11 G.M. Zaiad, Physico-chemical analysis of soils in Al-Khums city, Libya. J. Appl. Sci. Res., 2010, 6, 1040-1044.

12 E.A. Dutra, D.A.G. da Costa e Oliveira, E.R.M. Kedor-Hackmann and M.I.R.M. Santoro, Determination of sun protection factor (SPF) of sunscreens by ultraviolet spectrophotometry, Braz. J. Pharm. Sci., 2004, 40, 381-385. 
13 L. Mbanga, M. Mulenga, P.T. Mpiana, K. Bokolo, M. Mumbwa and K. Mvingu, Determination of Sun Protection Factor (SPF) of Some Body Creams and Lotions Marketed in Kinshasa by ultraviolet spectrophotometry, Int. J. Adv. Res. Chem. Sci., 2014, 1, 7-13.

14 W.K. Ng'etich, E.M. Mwangi, J. Kiptoo, C.A. Digo and J.O. Ombito, In vitro determination of Sun Protection Factor on clay used for cosmetic purposes in Kenya. Chem. Mat. Res., 2014, 7, 25-30.

15 J.E. Boulingui, C. Nkoumbou, D. Njoya, F. Thomas and J. Yvon, Characterization of clays from Mezafe and Mengono (Ne-Libreville, Gabon) for potential uses in fired products. Appl. Clay Sci., 2015, 115, 132-144.

16 J.d.S. Favero, J. Parisotto-Peterle, V. Weiss-Angeli, R.N. Brandalise, L.B. Gomes, C.P. Bergmann and V. dos Santos, Physical and chemical characterization and method for the decontamination of clays for application in cosmetics. Appl. Clay Sci., 2016, 124-125, 252-259.

17 S.F. Mpuchane, G.E. Ekosse, B.A. Gashe, I. Morobe and S.H. Coetzee, Microbiological characterization of southern African medicinal and cosmetic clays. Int. J. Environ. Heal. Res., 2010, 20, 27-41.

18 L. Montenegro, L. Rapisarda, C. Ministeri and G. Puglisi, Effects of lipids and emulsifiers on the physicochemical and sensory properties of cosmetic emulsions containing vitamin E. Cosmetics, 2015, 2, 35-47.

19 I.S. Mohammad, H.M.S. Khan, A.I. Arshad, H. Ijaz, P. Banerjee, A.U. Khan, Aftab-Ullah and A.Z. Juthi, In vitro characterization and assessment of cosmetic potentials of W/O emulsion cream containing $2 \%$ prosopis cineraria extract. Acta Pol. Pharm.-Drug Res., 2015, 72, 1233-1238.

20 P.S. Nayak and B.K. Singh, Instrumental characterization of clay by XRF, XRD and FTIR. Bull. Mater. Sci., 2007, 30, 235-238.

21 Q. Mohsen and A. El-maghraby, Characterization and assessment of Saudi clays raw material at different area. Arab. J. Chem., 2010, 3, 271-277.

22 A.G. Olaremu, Physico-chemical characterization of Akoko mined kaolin clay. J. Min. Mat. Charact. Eng., 2015, 3, 353-361.

23 A. Jaiswal, S. Banerjee, R. Mani and M.C. Chattopadhyaya, Synthesis, characterization and application of goethite mineral as an adsorbent. J. Environ. Chem. Eng., 2013, 1, 281-289.

24 S. Fadil-Djenabou, P. Ndjigui and J.A. Mbey, Mineralogical and physicochemical characterization of Ngaye alluvial clays (northern Cameroon) and assessment of its suitability in ceramic production. J. Asian Ceram. Soc., 2015, 3, 5058.

25 M.I. Carretero and M. Pozo, Clay and non-clay minerals in the pharmaceutical industry Part 1. Excipients and medical applications. Appl. Clay Sci., 2009, 46, 73-80.

26 D. Mwalongo and N.K. Mohammed, Determination of essential and toxic elements in clay soil commonly consumed by pregnant women in Tanzania. Radiat. Phys. Chem., 2013, 91, 15-18.

27 A. Lopez-Galindo, C. Viseras and P. Cerezo, Compositional, technical and safety specification of clays to be used as pharmaceutical and cosmetic products. Appl. Clay Sci., 2007, 36, 51-53.

28 D. Tsozue, A.N. Nzeugang, J.R. Mache, S. Loweh and N. Fagel, Mineralogical, physico-chemical and technological characterization of clays from Maroua (Far-North, Cameroon) for use in ceramic bricks production. J. Build. Eng., 2017, 11, 17-24.

29 I. Khiari, S. Mefteh, R. Sanchez-Espejo, P. Cerezo, C. Aguzzi, A. Lopez-Galindo, F. Jamoussi and C.V. Iborra, Study of traditional Tunisian medina clays used in therapeutic and cosmetic mud-packs. Appl. Clay Sci., 2014, 101, 141-148.

30 A.N. Odoma, N.G. Obaje, J.I. Omada, S.O. Idakwo and J. Erbacher, Mineralogical, chemical composition and distribution of rare earth elements in clay-rich sediments from southeastern Nigeria. J. Afr. Earth Sci, 2015, 102, 50-60.

31 J.R. Odilon Kikouama, K.L. Konan, A. Katty, J.P. Bonnet, L. Balde and N. Yagoubi, Physicochemical characterization of edible clays and release of trace elements. Appl. Clay Sci., 2009, 43, 135-141.

32 R. Morekhure-Mphahlele, W.W. Focke and W. Grote, Characterization of vumba and ubumba clays used for cosmetic purposes. S. Afr. J. Sci., 2017, 113, 1-5.

33 J.S. Gushit, P.N. Olotu and S. Maikudi, Overview of the availability and utilization of kaolin as a potential raw material in chemicals \& drugs formulation in Nigeria. Continental J. Sustainable Development, 2010, 1, 17-22.

34 G.P. Ojo, U.G. Igbokwe, C.J. Egbuachor and K.K. Nwozor, Geotechnical properties and geochemical composition of kaolin deposits in parts of Ifon, Southwestern Nigeria. Am. J. Eng. Res., 2017, 6, 15-24. 